\title{
Assessing and Improving Flood and Landslide Community Social Awareness and Engagement via a Web Platform: The Case of Italy
}

\author{
Daniele F. Bignami $^{1} \cdot$ Alessio Dragoni $^{2} \cdot$ Giovanni Menduni $^{3}$
}

Published online: 6 December 2018

(C) The Author(s) 2018

\begin{abstract}
Italy is significantly affected by ever-present flood and landslide risks and has experienced many disasters. Local social awareness and engagement, however, differ and need to be increased by decision makers and citizens through improvements in risk preparedness. With this aim, the \#italiasicura web platform was developed by Fondazione Politecnico di Milano and released in 2015 to show country to local level hazard maps and risk reduction projects in Italy. Any stage of the user experience with the platform can be shared via social media. Using this tool, an awareness-oriented web analytics process was structured to develop a set of indicators for the increase of knowledge linked to flood and landslide hazards. In so doing, it is possible to measure community disaster awareness actions and competence in the area of hazard knowledge. This article presents the results obtained by using data from the platform.
\end{abstract}

Keywords Community disaster risk awareness · Disaster risk reduction - Hazard knowledge

indicators $\cdot$ Italy $\cdot$ Risk reduction Web platform

Daniele F. Bignami

daniele.bignami@fondazione.polimi.it

1 Project Development Department, Fondazione Politecnico di Milano, 20133 Milan, Italy

2 SciamLab S.r.l, 00193 Rome, Italy

3 Civil and Environmental Engineering Department, Politecnico di Milano, 20133 Milan, Italy

\section{Introduction}

Italy is chronically prone to flood and landslide hazards. Official government data ${ }^{1}$ show the extension of floodprone areas for different hazard levels according to the European Council's 2007 flood directive (Directive 2007/60/EC ${ }^{2}$ ). Plains make up roughly one-quarter of the Italian national territory (about 70 thousand of $301,338 \mathrm{~km}^{2}$ ), and these are the areas where most buildings, human activities, and infrastructures are located. More than one-third of the plains is prone to medium probability floods (as defined by the European Council's 2007 flood directive, with a return period likely to be greater or equal to 100 years). A similar situation exists with regard to landslide-prone areas-the Italian national landslide inventory (IFFI-Inventario dei Fenomeni Franosi in Italia) (Trigila et al. 2010) contains information on 482,272 landslides (classified as active, reactivated, suspended, dormant, stabilized, and relicts), for a total landslide area of $20,500 \mathrm{~km}^{2}$ or $6.8 \%$ of the country's area (Marchesini et al. 2014).

A recent study reported a total of 12,702 fatalities caused by floods and landslides since the beginning of the twentieth century (ANCE-CRESME 2017), but these counts are strongly approximated. Mediterranean storms often produce fatalities that are not registered in flood and landslide damage reports-when, for example, a national state of emergency is not declared by the government and such fatalities are recorded as road accidents, or casualties due to thunderstorms or lightning.

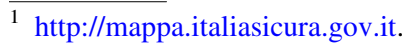

2 https://www.eea.europa.eu/policy-documents/directive-2007-60-ecof.
} 
The same report indicated that the current economic impact due to flood and landslide events can be conservatively estimated at an average of 2.45 billion euros per year, roughly $0.16 \%$ of GDP, taking into account only direct damages. The situation might worsen if no actions are taken to deal with the changing hazard situation under climate change (IPCC 2012, 2014; Medri et al. 2013), particularly when considering the heavy public debt of the country and the difficulties in allocating reconstruction funds.

Government policies against flood and landslide risks, especially in the last decades, have mainly focused on physical infrastructures, such as levees, river polders, and diversion channels. Risk reduction investments until recently have been relatively small compared to the requests from river basin authorities' planning departments. ${ }^{3}$ Without a strategy that is integrated with other forms of risk management, as stated by the United Nations International Strategy for Disaster Reduction (UNISDR) in the Sendai Framework for Disaster Risk Reduction 2015 2030 (UNISDR 2015), no amount of investment in physical infrastructure can reduce risk and vulnerability to zero or at least to an acceptable level. The EC directive 2007/60/ EC stressed that action has to be focused on the assessment and management of risk through a mix of multiple approaches and measures. One of these concurrent approaches, which also influences the recovery process, is strengthening the social infrastructure that affects community social awareness and engagement.

\section{Knowledge First-Building Community Social Awareness and Engagement at National and Local Levels}

To achieve a clear understanding of hazard and risk in a place is a difficult task for the people living there. River floods form at the scale of the whole hydrographic basin, and the probability of risk is often of little meaning to nonexperts. Building physical infrastructure for risk reduction should depend on long-term policies and not be decided just as a consequence of recent disasters. Community engagement helps people to be more oriented towards the common good and to understand the value of investments that do not necessarily have an immediate return. With this view, a strong community helps to address an integrated strategy of risk management.

A comprehensive understanding of hazard and a familiarity with the geographic context and social conditions

\footnotetext{
${ }^{3}$ In Italy the river basin authorities have been in charge of programming investment request for physical infrastructures since 1989.
}

(vulnerabilities included) results in information that may be used in verifying mitigation and preparedness actions by decision makers and in adopting self-protection measures (Lewis and Kelman 2010). Risk communication and information are critical parts of the process and positive contributions to creating trust and a sense of community, and to triggering decision-making progression-generally people support strategies they understand, but existing systems frequently fail to adequately incorporate their suggestions and interests (Pine 2015). Poor communication is still among the key challenges that influence the disaster management cycle and need more empirical research in order to enhance the management of disasters in the future (Pathirage et al. 2012). Social media have great potential for enhancing communications between people and government agencies at all levels (Yates and Paquette 2011), and specific and local knowledge could be used to form decisions in the flood risk management processes related to the European Union (EU) flood risk management directive (Fleischhauer et al. 2012).

Unfortunately, assessment and management of flood and landslide risks in Italy are rather complicated. The responsibilities for decision-making actions and funding are dispersed among a large number of different administrations, both at the national (Ministries of Environment, Public Works and Agriculture, Department of Civil Protection, River Basin Authorities) and the local administration levels (regions, provinces, and municipalities). Due to this fact it is not an easy task to participate in the hazard analysis process (Alexander 2000) to help build solutions, to keep a clear record of all investments in structural works, and above all, correlate them to the corresponding gain in terms of risk reduction within an integrated strategy. It is particularly difficult to keep administrative attention on hazard-prone areas where only minor disasters occurred in the recent past and were addressed by mobilizing only local resources. But learning to live with uncertainty, crisis, and disturbances, such as natural hazards, requires building an institutional memory of past events.

Many authors underline that disaster reduction has to focus also on strengthening community-based disaster education, in order to improve public knowledge and skills in disaster prevention and relief (Takeuchi et al. 2012; Chou and Wu 2014). Risk communication is a key step in the disaster risk management process and in community events, public communication, consultation, and public participation. New solutions have to be investigated to trigger the active participation of residents in community affairs related to disasters, with the aim of cultivating particular traits in communities such as trust, reciprocity, and collective action. In so doing, one fundamental driver of community social awareness and engagement could be 
expanded, increasing the chances not only for improving emergency preparedness, but also the social cohesion that could be tapped after future disasters.

To address the disaster prevention and risk management challenges, the Italian government in 2014 instituted a special office for hydrogeological disaster prevention under the direct supervision of the Prime Minister. Among the activities of this special office, the \#italiasicura platform ${ }^{4}$ was promoted by the government and developed by the Politecnico di Milano Foundation starting from 2015. The platform is a first step in using web resources, particularly social networks, to share results of hazard analyses and activate and develop awareness and engagement assets against flood and landslide risks through the spread and improvement of knowledge on potential local floods and landslides. The main purposes of the platform are to:

(1) Provide an updated, high spatial resolution framework on flood and landslide hazards (and on some elements at risk) that is coordinated at the national scale to improve the awareness of risk through a powerful geographic, user-friendly interface;

(2) Share real-time data about ongoing physical infrastructure construction, including details such as status, people in charge, budget and cash flow, time elapsed, and the date scheduled for the completion of the construction work, to develop public engagement and civic control;

(3) Give a well-defined, real-time image of the impact of major flood and landslide events by providing all details on national emergencies such as the budget allocated by the government for immediate rescue activities and related cash flow, people in charge, certified damages, and the end date of the national state of emergency;

(4) Provide an efficient procedure for an immediate sharing of all information through major social media networks to strengthen the sense of community and forms of social organization;

(5) Allow easy, real-time data updates and synchronization with other official information sources.

\section{Main Features of the \#italiasicura Web Platform}

The \#italiasicura web platform mainly consists of three pages. The first is related to the mid- and long-term situation of hazards. The map shows flood hazards in three classes according to the EU flood directive, and landslide hazards in 5 classes, for the whole country. Data of some elements at risk are also aggregated at different scales, such

\footnotetext{
${ }^{4}$ http://mappa.italiasicura.gov.it.
}

as for exposed surface area, number of people, schools, and cultural heritage. Through a street-address search the user can, for example, evaluate hazards related to his/her home. On the same map all ongoing risk mitigation work is shown and current progress status data can be extracted by clicking on the placemarker. More than 4000 worksites are reported and regularly updated (Figs. 1, 2). This allows a clear view of the relationship between hazard and mitigation at different sites. The second page focuses on national emergencies (short-term situation) and presents all data aggregated on the regional scale (Fig. 3). The third page, with text and graphics, allows several simple queries and rankings of the main parameters, for example, data on work related to disaster risk mitigation summarized by regions, provinces, and municipalities.

The platform is based on a spatial interface. A map on the screen is associated with an underlying database system. All information is presented in a contextual form based on coordinates and the zoom level. The first two pages start with the national map. A text box self-customizes and aggregates data on the actual zoom level. A new URL is generated for any event generated by the user. Through this function or by selecting any available entity on the map, any stage of the user experience can be shared immediately via social media using a convenient and unique system-generated URL.

\subsection{Base Geographic Information Layers}

The National Institute of Statistics (ISTAT-Istituto Nazionale di Statistica) ${ }^{5}$ releases map layers and statistical data related to five nested levels of aggregation: national, regional (20 items), provincial (109 items), municipal (8093 items), submunicipal (76,308 items), and census section (366,465 items). The boundary network of the lowest level (that is, the census section) is the highest resolution of the statistical analysis and corresponds to areas that encompass a maximum of 400 census units (such as families). In urban areas census sections usually coincide with a block, with an average area of $0.82 \mathrm{~km}^{2}$. Data at the census section level are used in the background to guarantee the accuracy of the computations. As the mouse wheel is turned (or plus or minus are clicked on the mouse icon), the aggregation scale is modified according to the zoom level. Results are constantly presented in the text box.

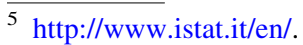




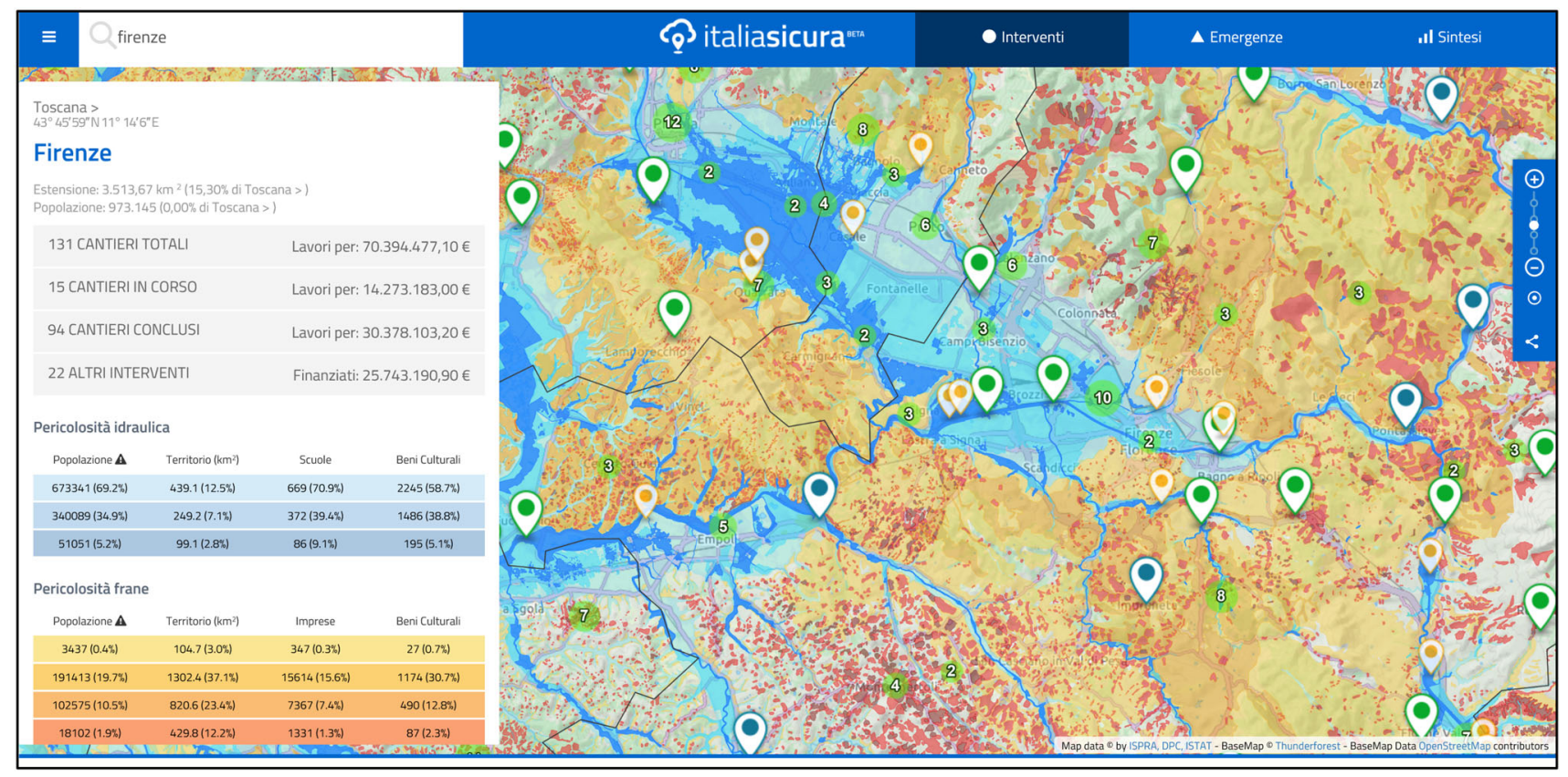

Fig. 1 Screenshot of a portion of the territory of Florence Province on the \#italiasicura platform, showing flood and landslide hazards, data on risk, and physical works related to disaster risk mitigation

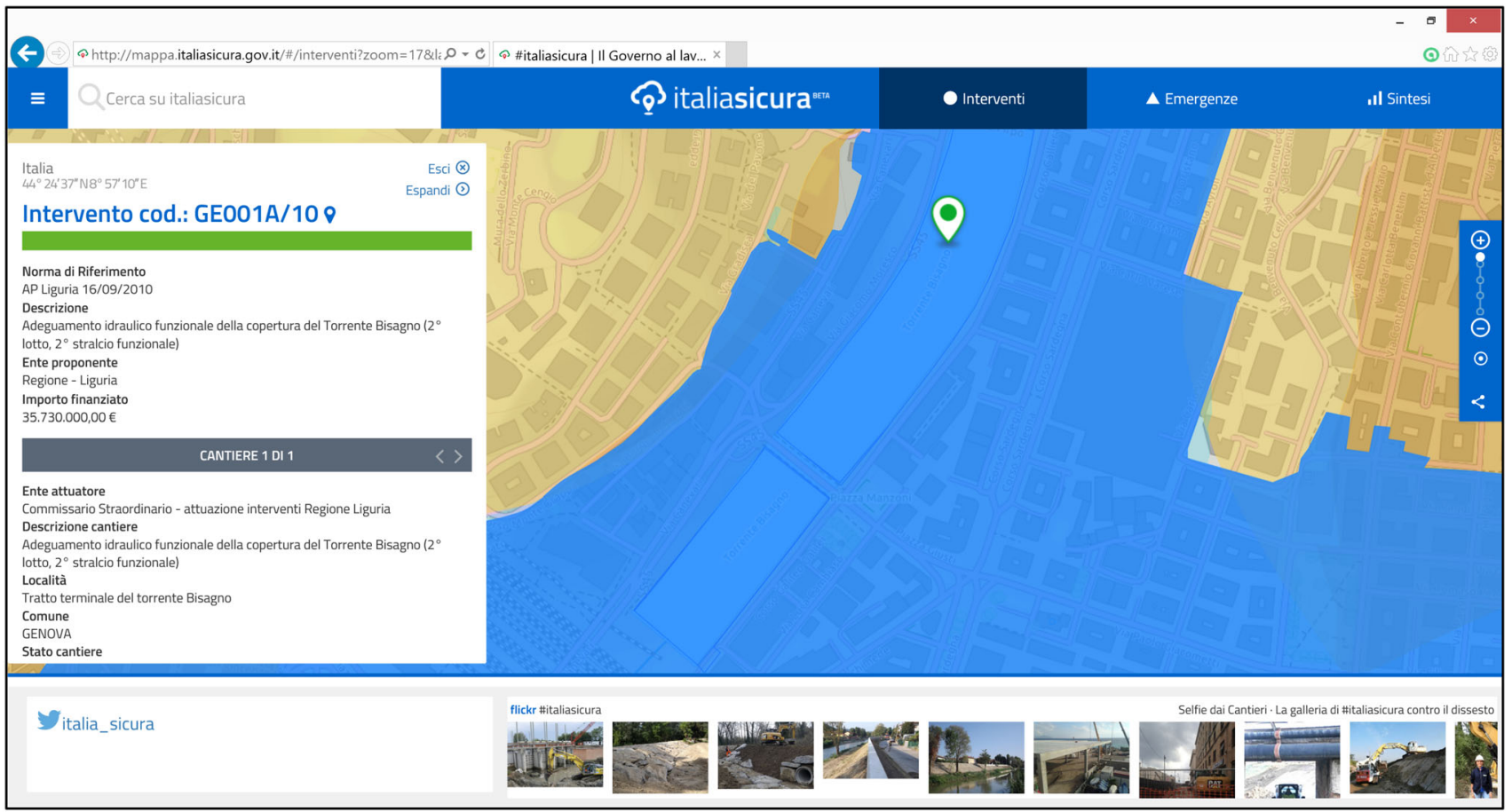

Fig. 2 Screenshot of a portion of the territory of Genoa (along the Bisagno River), on the \#italiasicura platform, precisely showing flood hazards and ongoing physical works and giving the connected information

\subsection{Works for Disaster Risk Mitigation and Emergency Details Data}

One of the first results has been the finalization-in cooperation with the Institute for Environmental Protection and Research (ISPRA-Istituto Superiore per la Protezione e la Ricerca Ambientale) ${ }^{6}$ - of the existing platform

\footnotetext{
${ }^{6}$ http://www.isprambiente.gov.it/en.
} 


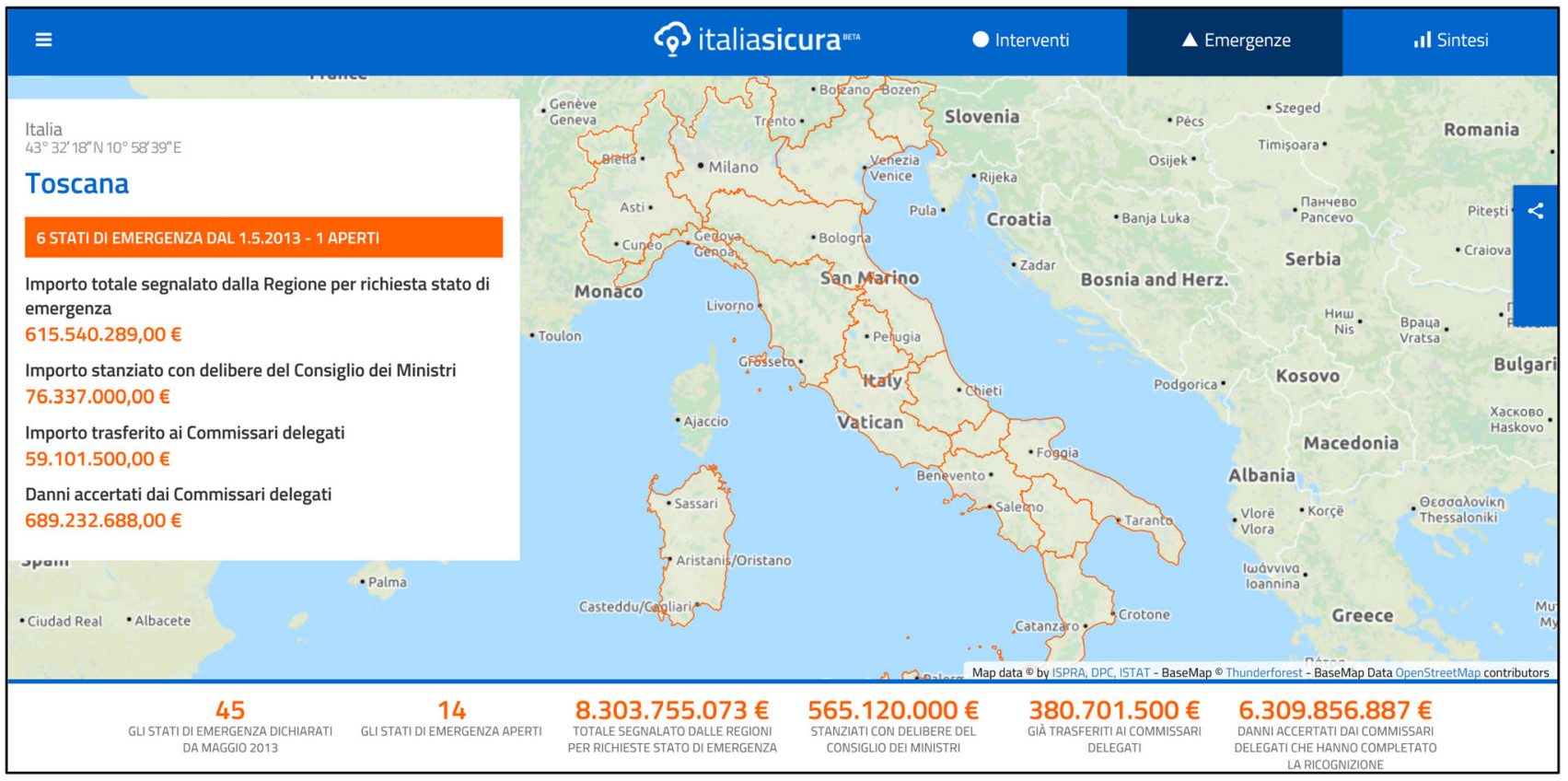

Fig. 3 Screenshot of the second page of the \#italiasicura platform, showing data on emergencies

Rendisweb, ${ }^{7}$ a unique database on public works against flood and landslide risks (Gallozzi et al. 2008; Campobasso et al. 2013). Each record contains coordinates, all technical and economic data, and status of the work, in order to gather a unique and integrated view about physical infrastructures at the national scale. At the same time, a database was developed by the National Civil Protection Department ${ }^{8}$ with essential data related to national emergencies, particularly with regard to people in charge, budget, cash flow, and damage assessment.

\subsection{Hazards and Elements at Risk Data}

In cooperation with ISPRA, flood-prone areas (updated on the basis of the EU flood directive) and landslide data from basin district authorities and the Italian Landslide Inventory of the IFFI Project (Trigila et al. 2007, 2010, 2013) have been mapped as a unique national mosaic, which as open data is also available for downloading. Before \#italiasicura was launched these data were only available at the district scale on district authority websites without any snapshot view at the national scale.

To give a general idea of the potential risk, data for a number of typical elements such as exposed surface area, number of residents, schools, and cultural heritage are aggregated for the different hazard classes (both for flood and landslide hazards) and presented in the "dynamic query window." The aggregation is performed

\footnotetext{
${ }^{7}$ http://www.rendis.isprambiente.it/rendisweb/.

${ }^{8}$ http://www.protezionecivile.gov.it/.
}

automatically, based on the mouse position and the zoom level, on the administratively nested boundaries (Table 1).

All data for the maps and elements at risk are directly gathered daily as web services by the owner administrations and kept current. The same sources allow downloading as open data.

\section{Assessing Levels of Awareness and Engagement through Web Analytics}

Classic website analytics data, such as users, number of sessions, or number of new users, allow evaluation of the contribution of \#italiasicura in assessing and developing awareness and engagement in the prevention and management of geohydrological risks at the national level. This power of the web provides an extraordinarily deep characterization of the users of any service. Indicators can enable the advancement of understanding of the multidimensional nature of the interactions between communities and natural risks, and contribute to providing a metric that is easily understood and applicable to the decision-making process.

\subsection{The Web Analytics Process}

Web analytics are generally considered an essential tool for business and market research, particularly to achieve a quantitative measure of the results of information and advertising campaigns and, more generally, to assess and 
Table 1 Aggregation scale for elements at risk on the \#italiasicura website

\begin{tabular}{lc}
\hline Scale & Average size $\left(\mathrm{km}^{2}\right)$ \\
\hline Country (total) & 301,338 \\
Regions & 15,067 \\
Provinces & 2816 \\
Municipalities & 38 \\
Submunicipal sites & 4 \\
\hline
\end{tabular}

improve the effectiveness of strategies and actions. Basically, it allows an overall quantitative assessment of website traffic, giving a number of key information tracking parameters such as user positions and times of access, type of platform, browser, and a huge number of more or less accurate profiling characteristics. Our web analytics process consists of the following steps:

- Collection, selection, and processing of data regarding the users of the \#italiasicura web platform;

- Development of key performance indicators (KPIs) as hazard knowledge proxies;

- Formulation of an updated propaedeutic framework towards community social awareness strategies.

Among the data recorded, based on recent works (Chen et al. 2013; Garbutt et al. 2015; Miles 2015; Yoon et al. 2015; de Loyola Hummell et al. 2016), we selected the following indicators and the related data were collected via the usual commercial analytics tools:

- Current date of the sessions (day index);

- Geographic location of the user (down to municipal level);

- Related number of sessions $\left(n_{s}\right)$ and new sessions (in $\%)\left(n_{\% s}\right)$;

- Number of new users $\left(n_{u}\right)$;

- Average duration of the sessions $\left(d_{s}\right)$;

- Number of pages per session (Pps).

\subsection{A Preliminary Set of "Hazard Knowledge" Web-Based Indicators}

We present here an analysis of the time history of the first year after the platform was officially released (14 April 2015). The time series can be divided into four periods:

(1) "Underground" from 14 April 2015 (when the platform was first published) to 20 May 2015 (official presentation press conference), during which only a selected set of colleagues and people from other institutions were made aware of the publication;
(2) "Honeymoon" from 21 May 2015 to 29 May 2015, after the public launch of \#italiasicura at Chigi Palace in Rome from the press room of the Italian Prime Minister; during this period a massive number of sessions were generated thanks to the promotion of the new platform put in place via media and social media;

(3) "Running-in of flood hazard maps" from 30 May 2015 to 20 November 2015, during which the \#italiasicura platform was online publishing (for the first time) the complete national mosaic of flood hazards in three classes;

(4) "Running-in of landslide hazard maps" from 21 November 2015 to 20 May 2016, after a significant upgrading by adding maps and information on landslide hazards in five classes.

Table 2 shows the data on related number of sessions.

A "session" is a group of user interactions with a website that take place within a given time frame. A single session, for example, can contain multiple page views, events, social interactions, or e-commerce transactions. The number of sessions (per day, per month, or per year) on the \#italiasicura website therefore can be a good quantitative measure of the level of interest among people. Since flood and landslide hazard mapping was introduced in Italy by a 1998 law and the whole mosaic was only completed between 2005 and 2010, the topic is still relatively new and not well-known in Italy.

\subsection{Correlation between Data Access and Disasters}

The data reveal both relatively low and quite high numbers of sessions during the "underground" and "honeymoon" periods but these have no particular statistical value in the medium term. It is more useful to investigate the general correlation between significant flood and landslide events in Italy (plus some significant cases outside Italy) and spikes in \#italiasicura analytics data such as users, page visited, and number of sessions.

A good example of this interaction is the case of the Livorno (Tuscany, Italy) flood of 9 September 2017 where an extreme rainfall event caused nine fatalities, probably due to the occurrence of problems in the emergency management chain. On 24 November 2016, another flood event had hit nearly the whole Piedmont region in northwestern Italy, with widespread damages and one fatality. In the days following both of these events peaks were observed in the number of sessions at the \#italiasicura website as people became interested in checking the hazard level in the surroundings of their homes (Fig. 4).

About $80 \%$ of the users in those days were "new users." Technically a "new user" is a person who has not visited a 
Table 2 \#italiasicura data on sessions in the four identified periods in the time from 14 April 2015 to 20 May 2016

\begin{tabular}{lllll}
\hline Periods & 1 & 2 & 3 & 4 \\
\hline Number of sessions $\left(n_{s}\right)$ & 700 & 4164 & 7947 & 11,397 \\
Number of days $\left(n_{d}\right)$ & 37 & 9 & 175 & 181 \\
Sessions per day $(S p d)$ & 18.92 & 462.67 & 45.41 & 62.97 \\
\hline
\end{tabular}

specific site in the last 2 years. In reality this assumes that the user only had one device, one browser, did not use an "ad-blocking" software, and never had cleared his Internet browsing history. The ratio between "new users" and total users can thus be considered as a proxy of the engagement process triggered by the platform.

To discuss the topic more quantitatively, the time history of the first year of \#italiasicura was examined in terms of number of sessions. The correlation between access and the peaks of flood or landslide events was analyzed in order to check if the platform was perceived by people as a reliable source of information about the hazards. In order to define the occurrence of "session peak," we tested if the relative difference

$\Delta=\frac{C-A v}{A v}$

between current value $C$ of the time series and the 7-day moving average $A v$ centered on the same day results in a value greater than $50 \%$ of $A v$. The weekly moving average window filters usual session rate variations due to the effect of weekends, leaving unaffected variations related to longer periods (monthly, seasonal).

The event list was derived from the Research Institute for Geo-Hydrological Protection of the Italian National Research Council (IRPI-CNR, Istituto di Ricerca per la Protezione Idrogeologica-Consiglio Nazionale delle Ricerche), from their "Report on Hydrogeological Disaster Events in Italy" " that is available online (IRPI-CNR 2016, 2017). These data, limited to events with causalities, were integrated by us with further events data derived from the news for events with clear and high impact due to a wide coverage by the national media (television and press). A peak was correlated with an event if it occurred on the same day of the event or within the next 3 days.

Figure 5 shows the number of sessions indicator time history from 1 April 2015 to 20 May 2016 (including the time interval corresponding to the periods 3 and 4 of Sect. 4.2, almost equal to 20,000 sessions). The IRPI national portal on flood and landslide disasters with causalities reports 37 events for the same period. We added four further events that had a high national media

\footnotetext{
9 http://polaris.irpi.cnr.it/report.
}

coverage- - a tornado in the Marche region in eastern Italy, a huge tidal flood in Venice, and two international events: the Paris (3 June 2016) and United Kingdom (27 December 2016) floods.

The results are summarized as follows:

- Peaks in number of sessions: 54.

- Total number of events: 41 .

- Matching cases between a peak and an event: 20 (49\%).

Several session peaks that cannot be matched with hazard events can be explained by seminars, courses, and meetings in which the platform was somehow described, discussed, or used. One can note how some events are close to each other in time and how the markers result to be superimposed in Fig. 5.

\subsection{Geographic Location}

Further information can be derived from geographic data on the location of the users. Differentiating "Sessions per day" and "Sessions peak" indicators by location, national and local governments can, for example, allow the implementation of strategies that address the "weak" (or most in need) places of the country.

"New users," "new sessions," "duration of the sessions," and "number of pages per session" at the national, regional, or local scale, have the capability of suggesting more precisely the growth of the user pool (the number of new users) and the degree of the knowledge acquired on the topic of flood and landslide hazards. Thus we suggest the following new indicators: "user growth"; "learning degree"- as equal weight arithmetic mean of the "duration of the sessions" and the "number of pages per session" over the mean value for the year; and "learning preservation"-as the behavior (or trend) of the data of the complement to $100 \%$ of new sessions (as a suggestion of the degree of the awareness acquired about hydrogeological risk, being an indicator of long-term contacts with the platform). Table 3 shows the data for 10 cities. Milan and Rome were excluded because of data distortion due to technical faults related to mobile provider locations.

The same data can be examined in relation to demography (ISTAT, 15th population and housing census of $2011^{10}$; ISTAT 2013). Table 4 shows that the highest ratio between new users and total population is found in Cosenza (Calabria), which experienced a huge flood in August 2015, and the second is in Modena (Emilia Romagna), which in 2014 was also flooded due to the failure of Secchia River levees, with one fatality and more than 200 million euros in direct damages. Cosenza also

\footnotetext{
${ }^{10}$ https://www4.istat.it/en/population-and-housing-census/popula tion-and-housing-2011.
} 

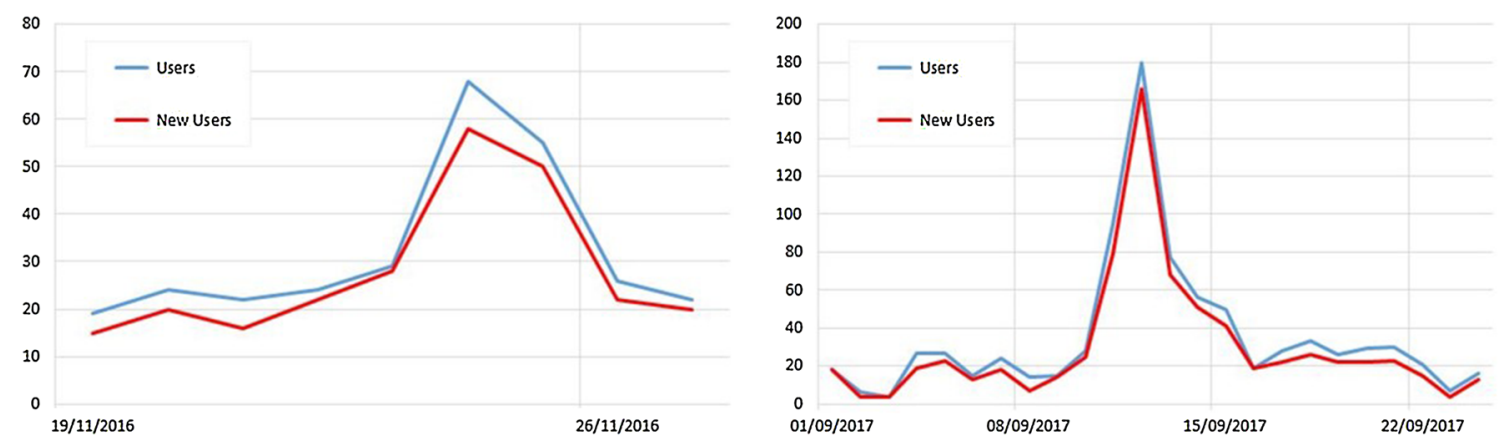

Fig. 4 Number of users (blue line) and new users (red line) at the \#italiasicura website 19 to 28 November 2016 (left), and 1 to 25 September 2017 (right). Peaks occurred in the days immediately following the Piedmont (24 November 2016) and Livorno (9 September 2017) flood events

Table 3 \#italiasicura data on the number of new users, new sessions, the number of pages per session, and the duration of the sessions for a selected number of Italian cities in the period 14 April 2015-13 December 2015

\begin{tabular}{lllll}
\hline City & New users & \% New sessions & Pages/session & Average session duration \\
\hline Bologna & 343 & 76.73 & 2.22 & $00: 01: 50$ \\
Turin & 327 & 71.09 & 2.26 & $00: 02: 10$ \\
Florence & 291 & 77.19 & 2.31 & $00: 01: 46$ \\
Naples & 238 & 77.27 & 2.26 & $00: 01: 37$ \\
Genoa & 192 & 61.94 & 2.38 & $00: 02: 02$ \\
Modena & 180 & 77.59 & 1.91 & $00: 01: 13$ \\
Palermo & 154 & 69.06 & 2.85 & $00: 02: 02$ \\
Catania & 120 & 87.59 & 2.15 & $00: 01: 35$ \\
Bari & 119 & 84.40 & 1.95 & $00: 01: 23$ \\
Cosenza & 111 & 73.03 & 2.45 & $00: 02: 40$ \\
\hline
\end{tabular}

ranks first in average session duration and second in pages per session.

\subsection{Web-Based Hazard Knowledge Indicators}

The considerations discussed above show how web analytics on national government platforms can provide a set of hazard knowledge indicators (Table 5).

A similar and parallel set of indicators, thanks to the ease of sharing user experience via social media, could also be developed by researching Twitter and Facebook analytics, and monitoring and measuring tweets and posts from \#italiasicura.

\section{Conclusion}

The \#italiasicura platform is a government web platform promoted by the Italian government in cooperation with the Politecnico di Milano Foundation. The website presents hazard maps for floods and landslides at the national scale via a user-friendly and effective interface aimed at increasing community social awareness of and engagement with natural hazard risk reduction. The same portal presents data of recent events in terms of damages and emergency management and the progress of public works aimed at risk reduction. Dynamic predefined queries are provided, aggregating data according to the zoom scale. The metrics developed in this study will enable national and local governments and institutions to monitor progress in promoting social awareness, from a community competence point of view, in the country and in each local context down to the scale of about $4 \mathrm{~km}^{2}$. The developed set of hazard knowledge indicators appears applicable and operational to assess relative levels of awareness, both to compare awareness among places (with aggregation at different scales) and to analyze the trend of engagement proxies over time. The platform also enables a widespread community engagement with disaster risk reduction strategies and the development of new strategies, helping to identify those target communities where proactive measures are needed.

From the point of view of citizens, the \#italiasicura web platform gives them not only general knowledge, but also 
Table 4 \#italiasicura data on the number of new users for a selected number of Italian cities, compared with their population in the period 14 April 2015-13 December 2015

\begin{tabular}{llcc}
\hline City & New users & Population (2011) & New users/population (\%) \\
\hline Cosenza & 111 & 71,087 & 1.56 \\
Modena & 180 & 186,095 & 0.97 \\
Bologna & 343 & 397,430 & 0.86 \\
Florence & 291 & 362,215 & 0.80 \\
Catania & 120 & 318,669 & 0.38 \\
Turin & 327 & 871,377 & 0.38 \\
Bari & 119 & 326,191 & 0.36 \\
Genoa & 192 & 600,591 & 0.32 \\
Naples & 238 & 985,450 & 0.24 \\
Palermo & 154 & 731,958 & 0.21 \\
\hline
\end{tabular}

Table 5 Hazard knowledge indicators based on web analytics on a national government platform

\begin{tabular}{lllll}
\hline Indicator & Spatial scale & Temporal scale & Referred to population & Meaning \\
\hline Number of sessions & All & Medium Long & Yes & Overall increase of the level of information \\
Sessions per day & National/Regional & Medium Long & No & Background willingness to know \\
Session peaks & National/Regional & Short Medium Long & No & Emotional willingness to know \\
User growth & All & Medium Long & Yes & Knowledge dissemination effectiveness \\
Learning degree & All & Long & Yes & Degree of the acquired knowledge \\
Learning preservation & All & Long & Yes & Degree of the acquired awareness \\
\hline
\end{tabular}

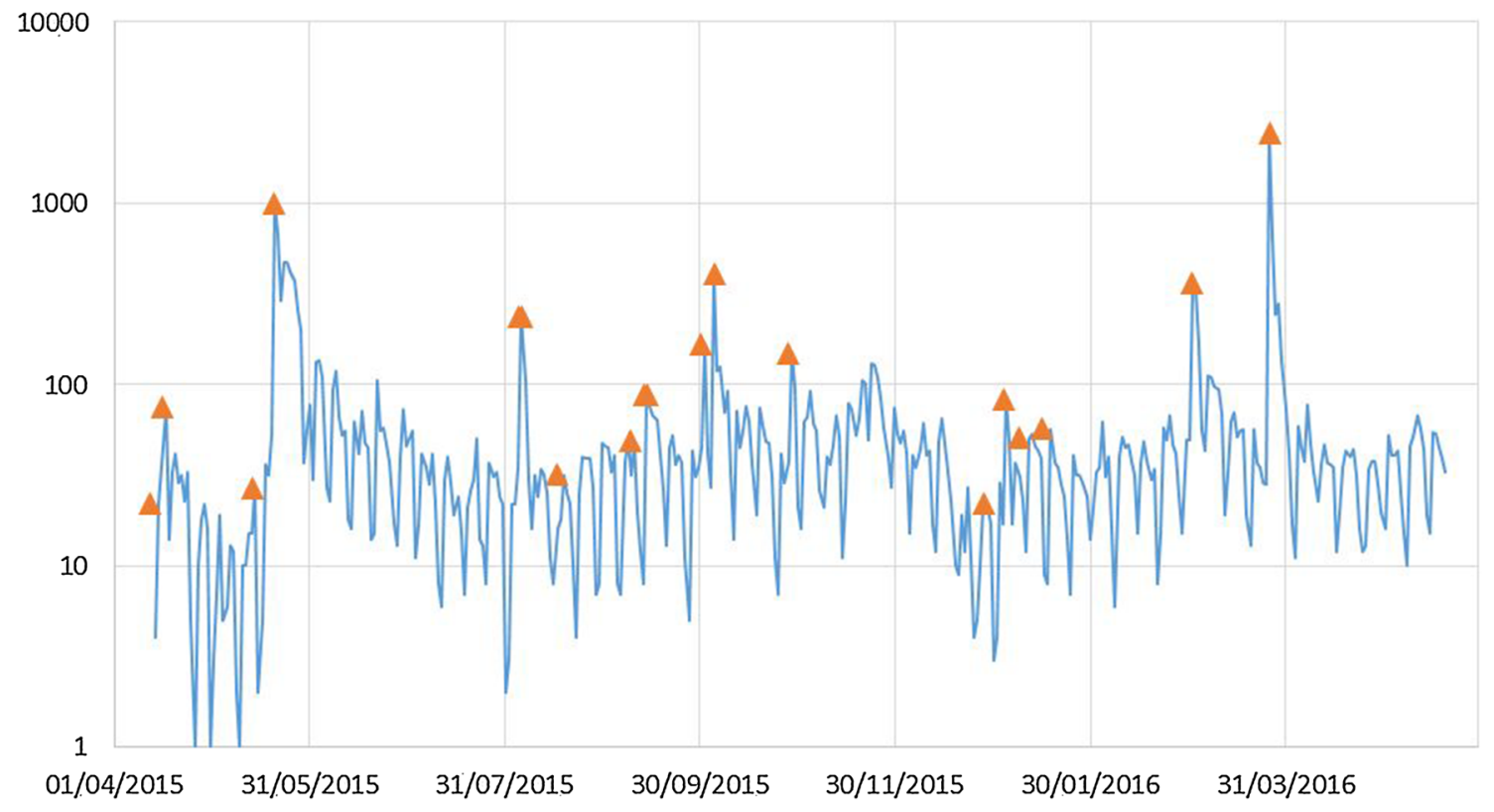

Fig. 5 Time history of the number of sessions at the \#italiasicura website, 1 April 2015 to 20 May 2016, and the flood events (yellow triangles) that were correlated with the session peaks. The y-scale is logarithmic 
accurate information, with the possibility of easily verifying on maps whether a place is included or not in a floodor landslide-prone area. The database on structural works toward hydrogeological risk reduction by the government and other institutions (offered by the platform) is also near completion. The \#italiasicura platform may also be useful for achieving easier dissemination of disaster certifications for buildings, such as the CePRED-Certification of the Predisposition of Resistance of Edifices to Disasters (Bignami 2014), or disaster and climate change adaptation reports about conditions in Italy (see Legambiente 2016, for example).

Future plans for the development of the \#italiasicura web platform are also conceived taking into consideration the possibility of integrating in the platform other data that are useful to enlarging the framework of knowledge of community social awareness related to flood and landslide hazards. Basic information on local emergency plans (at the communal level) and geo-data on potential soil water repellence changes caused by wildfires, that worsen flooding, could be added to the map.

A number of weaknesses should also be mentioned. The platform strongly depends on the availability of data released by different national agencies. The continuity of these web services has been supported by a strong will of the government but there is no law (or other legal or regulatory instruments) that guarantees the service in the future in the case of any change of strategies in national policies. Hazard maps are generally provided by regions and district authorities that often use different modeling tools. This leads to a certain discrepancy, which is often evident at regional borders and that can be overcome only with the release of national guidelines that are lacking at present. Data on the progress of public works depend on the update frequency by different administrations in charge. This could lead to different accuracy levels, sometimes misleading for statistical purposes.

Acknowledgements The work presented in this article is supported by AGID, the Agenzia per l'Italia Digitale (Agency for Digital Italy). Many of the input data used in the work are provided by the Italian ISPRA, the Istituto Superiore per la Protezione e la Ricerca Ambientale (Institute for Environmental Protection and Research). Data are also provided by the Dipartimento della Protezione Civile (Civil Protection Department) and the Dipartimento per le Politiche di Coesione (Cohesion Policy Department) of the Presidency of the Council of Ministers of the Italian Republic, and by the Agenzia per la Coesione Territoriale (Territorial Cohesion Agency) of the Italian government. The institutional coordination of the work has been possible mainly thanks to the support afforded by the Struttura di Missione Contro il Dissesto Idrogeologico e per lo Sviluppo delle Infrastrutture Idriche (Special Office for Hydrogeological Disaster Prevention), and the collaboration of the Ministry for the Environment and Land and Sea, and of the Ministry of Infrastructure and Transport of the Italian government. The authors are grateful to all the colleagues of the above-mentioned bodies for their constant and valuable assistance.

Open Access This article is distributed under the terms of the Creative Commons Attribution 4.0 International License (http://crea tivecommons.org/licenses/by/4.0/), which permits unrestricted use, distribution, and reproduction in any medium, provided you give appropriate credit to the original author(s) and the source, provide a link to the Creative Commons license, and indicate if changes were made.

\section{References}

Alexander, D. 2000. Confronting catastrophe. New York: Oxford University Press.

ANCE-CRESME (Associazione Nazionale Costruttori Edili - Centro Ricerche Economiche, Sociologiche e di Mercato nell'Edilizia/ National Association of Builders and Contractors - Center for Applied Research on Economics, Sociological Issues and Market Concerning Building Activities). 2017. Report on the state of risk of the Italian territory 2017 (Rapporto sullo stato di rischio del territorio italiano 2017). http://www.cresme.it. Accessed 30 Oct 2018 (in Italian).

Bignami, D.F. 2014. Towards a territorial multi-disaster buildings' resistance certification. New York: Springer.

Campobasso, C., G. Delmonaco, B. Dessì, P.L. Gallozzi, B. Porfidia, D. Spizzichino, F. Traversa, and G. Vizzini. 2013. Long term strategies and policies for geological and hydraulic risk mitigation in Italy: The ReNDiS project. In Landslide science and practice, ed. C. Margottini, P. Canuti, and K. Sassa, 39-45. Berlin: Springer-Verlag.

Chen, W., S.L. Cutter, C.T. Emrich, and P. Shi. 2013. Measuring social vulnerability to natural hazards in the Yangtze River Delta region, China. International Journal of Disaster Risk Science 4(4): 169-181.

Chou, J.S., and J.H. Wu. 2014. Success factors of enhanced disaster resilience in urban community. Natural Hazards 74(2): 661-686.

de Loyola Hummell, B.M., S.L. Cutter, and C.T. Emrich. 2016. Social vulnerability to natural hazards in Brazil. International Journal of Disaster Risk Science 7(2): 111-122.

Fleischhauer, M., S. Greiving, F. Flex, M. Scheibel, T. Stickler, N. Sereinig, G. Koboltschnig, P. Malvati, V. Vitale, P. Grifoni, and K. Firus. 2012. Improving the active involvement of stakeholders and the public in flood risk management: Tools of an involvement strategy and case study results from Austria, Germany and Italy. Natural Hazards and Earth System Sciences 12: 2785-2798.

Gallozzi, P.L., L. Guerrieri, D. Spizzichino, G. Vizzini, and C. Campobasso. 2008. The Rendis Project: Status of implementation and accessibility of data (Il Progetto Rendis: Stato Di Attuazione ed Accessibilità dei Dati). In Proceedings of the 12th ASITA National Conference, 21-24 Oct 2008, L'Aquila, Italy (Atti 12 Conferenza Nazionale ASITA-L'Aquila 21-24 ottobre 2008), 1185-1190 (in Italian).

Garbutt, K., C. Ellul, and T. Fujiyama. 2015. Mapping social vulnerability to flood hazard in Norfolk, England. Environmental Hazards 14(2): 156-186.

IPCC (Intergovernmental Panel on Climate Change). 2012. Managing the risks of extreme events and disasters to advance climate change adaptation. A special report of working groups I and II of the intergovernmental panel on climate change. Cambridge, UK: Cambridge University Press.

IPCC (Intergovernmental Panel on Climate Change). 2014. Climate change 2014: Synthesis report. Contribution of Working Groups 
I, II and III to the Fifth Assessment Report of the Intergovernmental Panel on Climate Change. Geneva: IPCC.

IRPI-CNR (Istituto di Ricerca per la Protezione Idrogeologica Consiglio Nazionale delle Ricerche/Research Institute for GeoHydrological Protection of the Italian National Research Council). 2016. Periodic report on the risk of the Italian population by landslides and by floods-Year 2015 (Rapporto periodico sul rischio posto alla popolazione Italiana da frane e da inondazioni-Anno 2015). http://polaris.irpi.cnr.it/wp-content/ uploads/report-2015.pdf. Accessed 2 Mar 2018 (in Italian).

IRPI-CNR (Istituto di Ricerca per la Protezione Idrogeologica Consiglio Nazionale delle Ricerche/Research Institute for GeoHydrological Protection of the Italian National Research Council). 2017. Periodic report on the risk of the Italian population from landslides and floods-Year 2016 (Rapporto Periodico sul Rischio posto alla Popolazione Italiana da Frane $e$ da Inondazioni-Anno 2016). http://polaris.irpi.cnr.it/wp-content/ uploads/report-2016.pdf. Accessed 2 Mar 2018 (in Italian).

ISTAT (Istituto Nazionale di Statistica/Italian National Institute of Statistics). 2013. Data from 15th population and housing census of 2011. https://www.Istat.it. Accessed 2 Mar 2018.

Legambiente. 2016. Italian cities to the challenge of climate-The impacts of climate change and adaptation policies (Le città italiane alla sfida del clima-Gli impatti dei cambiamenti climatici e le politiche di adattamento). https://www.legam biente.it/sites/default/files/docs/le_citta_italiane_alla_sfida_del clima_2016.pdf. Accessed 2 Mar 2018 (in Italian).

Lewis, J., and I. Kelman. 2010. Places, people and perpetuity: Community capacities in ecologies of catastrophe. ACME: An International Journal for Critical Geographies 9(2): 191-220.

Marchesini, I., F. Ardizzone, M. Alvioli, M. Rossi, and F. Guzzetti. 2014. Non-susceptible landslide areas in Italy and in the Mediterranean region. Natural Hazards Earth System Sciences 14: 2215-2231.

Medri, S., S. Venturini, and S. Castellari. 2013. Overview of key climate change impacts, vulnerabilities and adaptation action in Italy. Research Paper Issues RP0178, July 2013. Centro Euro Mediterraneo sui Cambiamenti Climatici (CMCC)/EuroMediterranean Center on Climate Change.
Miles, S.B. 2015. Foundations of community disaster resilience: Well-being, identity, services, and capitals. Environmental Hazards 14(2): 103.

Pathirage, C., K. Seneviratne, D. Amaratunga, and R. Haigh. 2012. Managing disaster knowledge: Identification of knowledge factors and challenges. International Journal of Disaster Resilience in the Built Environment 3(3): 237-252.

Pine, J.C. 2015. Hazard analysis: Reducing the impact of disaster, 2nd edn. Abingdon, UK: CRC Press, Taylor \& Francis Group.

Takeuchi, Y., W. Xu, Y. Kajitani, and N. Okada. 2012. Investigating risk communication process for community's disaster reduction with a framework of "Communicative Survey Method". Journal of Natural Disaster Science 33(1): 49-58.

Trigila, A., C. Iadanza, and L. Guerrieri. 2007. The IFFI project (Italian landslide inventory): Methodology and results. In Proceedings of the Experts Meeting on Guidelines for Mapping Areas at Risk of Landslides in Europe, 23-24 Oct 2007, Ispra, Italy, 15-18.

Trigila, A., P. Frattini, N. Casagli, F. Catani, G. Crosta, C. Esposito, C. Idanza, D. Lagomarsino, G. Scarascia Mugnozza, S. Segoni, D. Spizzichino, V. Tofani, and S. Lari. 2013. Landslide susceptibility mapping at national scale: The Italian case study. In Landslide science and practice, ed. C. Margottini, P. Canuti, and K. Sassa, 287-295. Berlin: Springer-Verlag.

Trigila, A., C. Iadanza, and D. Spizzichino. 2010. Quality assessment of the Italian Landslide Inventory using GIS processing. Landslides 7(4): 455-470.

UNISDR (United Nations International Strategy for Disaster Reduction). 2015. Global assessment report on disaster risk reduction 2015. Geneva: United Nations Office for Disaster Risk Reduction.

Yates, D., and S. Paquette. 2011. Emergency knowledge management and social media technologies: A case study of the 2010 Haitian earthquake. International Journal of Information Management 31(1): 6-13.

Yoon, D.K., J.E. Kang, and S.D. Brody. 2015. A measurement of community disaster resilience in Korea. Journal of Environmental Planning and Management 59(3): 436-460. 